\title{
Phenolic Antioxidants as Drugs for Alzheimer's Disease: Oxidative Stress and Selectivity
}

\author{
Peter Kovacic* \\ Department of Chemistry and Biochemistry, San Diego State University, USA
}

Submission: August 01, 2017; Published: October 04, 2017

*Corresponding author: Peter Kovacic, Department of Chemistry and Biochemistry, San Diego State University, San Diego, CA, USA,

Email: pkovacic@mail.sdsu.edu

\begin{abstract}
Oxidative stress (OS) is a well-recognized feature of Alzheimer's disease. However, evenup to the present time, there is controversy and conflicting results concerning the role of antioxidants (AO). This review provides evidence for the beneficial influence of phenols and phenolic ethers as AOs. Other mechanisms were advanced for these drugs previously; however, this report adds validity to the positive influence of AOs on Alzheimer's disease. An important aspect to be recognized is the variability of action with a class based on competing pathways. The AOs involved are the following: curcumin, sesamol, rivastigmine, galantamine, donepezil, and piperine.
\end{abstract}

Keywords: Phenolic antioxidants; Alzheimer's disease; oxidative stress

Abbreviations: AGE: Advanced Glycation End Products; OS: Oxidative Stress; ET: Electron Transfer; ROS: Reactive Oxygen Species; A0: Antioxidant; 4-HNE: 4-hydroxynonenal; RNS: Reactive Nitrogen Species

\section{Introduction}

Two of the pathological features of Alzheimer's disease are senile plaques (or neuritic plaques) and neuro fibrillary tangles, including amyloid- $\beta$ - peptides [1]. Suggested mechanisms for formation of these proteins include oxidation by reactive oxygen species (ROS) and reactive nitrogen species (RNS), advanced glycation end products (AGE) formation via oxidation and metal compound involvement, where AOs may have a significant impact. A recent review addressed AGE based on oxidative events [2] in which quinones comprise an important class of electron transfer (ET) agents that generate ROS and OS. The ET agents are often formed by oxidation of phenolic compounds that make up part of drugs and physiologically active species. The phenolic are the focus of this commentary.

\section{Discussion}

There is early literature before 2000 for elevated levels of oxidative damage in vivo in Alzheimer's disease [1]. The evidence involves elevations in 8-OH-dG, other DNA based oxidation products, protein carbonyls, nitro tyrosine, 4-hydroxynonenal (4-HNE), and other products from lipid peroxidation. Notably, 4-HNE is quite toxic to neurons and senile plaques are involved in oxidative insult. The iron in senile plaques may facilitate oxidative damage via ET suggesting that inflammation from plaques could play a role involving ROS and RNS generation [3].

The importance of OS in Alzheimer's disease has been well established [4] and is generally accepted. However, there remains uncertainty and debate over the role of AOs. The 2015 title raises the question, "should we keep trying antioxidant therapies?" [4] A study with vitamins $\mathrm{E}$ and $\mathrm{C}$ in Alzheimer's disease patients revealed no differences in clinical outcomes. No difference in clinical progression was seen with the AO ginkgo bilobaor with estrogen in Alzheimer's disease patients. The possible reasons for lack of beneficial effects were discussed; however, the study's conclusion was that more studies were needed to resolve the conflicting aspects. In other investigations, a current 2017 report stated that "Oxidative stress is an established dementia pathway, but it is unknown if the use of AO supplements can prevent dementia", with a focus on Alzheimer's disease [5]. Another earlier investigation stated that there is "evidence for the benefits of AOs based on therapeutic intervention in dementia are inconsistent" with reference to Alzheimer's disease [6].

This report adds support to the notion that AOs can play an important role in Alzheimer's disease. However, it should be emphasized that selectivity is an important factor in determining the outcome in which various factors are involved. This report deals with phenolic and/or phenolic ethers as AO in Alzheimer's disease. The class is well known to possess AO properties. However, prior literature pays little attention to this aspect, but instead emphasizes enzyme inhibition as the mode of action. These AO compounds comprise: curcumin, sesamol, rivastigmine, galantamine, donepezil, and piperine. 


\section{Curcumin}

Curcumin (Figure 1), a spice, is a phenol type and phenolic ether. The dike tone can undergo tautomerism to the ketoenol form. The compound displays a wide spectrum of drug and physiological activities, including AO action [7]. In a 2008 study, memory in people with Alzheimer's disease was improved [8]; which was later supported in a 2010 review noting this memory property as well [9]. Additionally, recent literature has indicated the potential of this substance in the treatment of Alzheimer's disease. Furthermore, curcumin inhibits amyloid $\beta$ protein, amyloid $\beta$ aggregation, deposition, and oligomerization. Improvement in animal models was noted. These reports indicate that curcumin may be a primary candidate for Alzheimer's disease therapy. Lastly, another study in 2005 demonstrated AO, anti-inflammatory and anti-amyloid activity in the aspects of Alzheimer's disease [10]. The AO aspect is particularly relevant, placing this structure in accord with ROS - OS -AO approach.

\section{Sesamol}

Sesamol (Figure 2), present in sesame, has the common phenolic and phenolic ether structures. Its AO properties have been known for some time [11,12]. Various physiological responses are elicited including antifungal, which was attributed to signaling $[13,14]$. Neuro inflammation appears to be involved in a number of neurodegenerative disorders reported, including Alzheimer's disease. Sesamol is reported to prevent inflammation induced memory impairment [15] and lessens inflammation in diabetic neuropathy. Moreover, modulation of the oxidative NO pathway by the phenolic prevents cognitive deficits in an Alzheimer's disease animal model [15]. Again, these properties fit the ROS - OS -AO mechanistic scheme.

\section{Rivastigmine}

Rivastigmine (Figure 3), a phenolic ester, is of interest as an agent for the treatment of mild to moderate Alzheimer's disease [16]. Esterases are common enzymes that catalyze the hydrolysis of esters. The hydrolytic cleavage can also be achieved by catalysis involving a proton. The result is the generation of an AO phenol. In addition, the compound is an acetyl cholinesterase inhibitor [17]. In this case, rivastigmine is in accordance with ROS-OS-AO and is achieved through its proposed phenolic metabolite.

\section{Galantamine}

Galantamine (Figure 4), a plant alkaloid phenolic ester, is used for the treatment of mild to moderate Alzheimer's disease, in addition to other memory disorders [18]. Along with others of this phenolic class, it is an acetyl cholinesterase inhibitor [19]. This appears to be another case in which a metabolite plays a key role. De methylation would yield an AO derivative, which is a widespread structure in this class. Dealkylation of phenolic ethers has been treated previously; for instance in the case of etoposide [20].

\section{Donepezil}

Donepezil (Figure 5), a phenolic di ether, is used as the standard palliative treatment of Alzheimer's disease [21]. Discussion of the mechanistic aspects for galantamine would also apply in this case. A report on autism indicated that the drug could improve speech [22]. Additionally, a recent review provides evidence for involvement of the ROS- OS-AO mechanism in autism [23].

\section{Piperine}

Piperine (Figure 6), an alkaloid spice responsible for the pungency of pepper and a catechol diether, has been investigated in Alzheimer's disease therapy. Also the drug enhances cognitive functions as well as the standard drug donepezil [24]. A dual mechanism appears to apply, namely AO activity and esterase inhibition. Additional modes of action are anti-apoptosis and anti-inflammation. Another study showed results superior to donepezil [25] in which OS was reduced. Numerous medicinal plants possess profound central nervous system (CNS) effects and $\mathrm{AO}$ activity [26]. Possible modes of action involve decreases in lipid peroxidation and esterase enzymes. A 2015 study revealed enhanced cognitive function; also, anti-inflammatory and anti-apoptotic effects were noted [27]. Again, like with the previously mentioned drugs, the ester may undergo catalysis resulting in the generation of an $\mathrm{AO}$ phenol.

(Figures 1-6). Alzheimer's disease Drugs.

\section{Conclusion}

This is the first of a planned series on brain diseases based on the unifying theme of ROS-OS-AO, which has been applied previously to many bioactive compounds and drugs. Also, a treatment of structure-activity relationship (SAR) for drugs relating to the various brain diseases discussed in this series of commentaries is forthcoming. A recent related review deals with autism [23].

\section{Acknowledgement}

The assistance by Thelma Chavez is acknowledged.

\section{References}

1. Halliwell B, Gutteridge JMC (1999) Free Radicals in Biology and Medicine, $3^{\text {rd }}$ ed., Oxford University Press. Oxford, UK p.749.

2. Kovacic P, Somanathan R (2014) Novel Mechanism for Advanced Glycation End Product (AGE) Toxicity: $\alpha$-Dicarbonyls, Electron Transfer, Radicals, Oxidative Stress, and Antioxidants, In: Laher I (Ed.) Systems Biology of Free Radicals and Antioxidants. Springer-Verlag Berlin Heidelberg p. 3405-3418.

3. Kovacic P, Somanathan R (2014) Inflammation and Anti-Inflammatory Agents - Reactive Oxygen Species and Toxicity, In: I. Laher (Ed.) Systems Biology of Free Radicals and Antioxidants. Springer-Verlag Berlin Heidelberg p. 3197-3216.

4. Ferreira ME, de Vasconcelos AS, da Costa Vilhena T, da Silva TL, da Silva Barbosa A, et al. (2015) Oxidative stress in Alzheimer's disease: Should we keep trying antioxidant therapies? Cell Mol Neurobiol 35(5): 595614. 


\section{Novel Approaches in Drug Designing \& Development}

5. Kryscio RJ, Abner EL, Caban-Holt A, Lovell M, Goodman P, et al. (2017) Schmitt, Association of antioxidant supplement use and dementia in the prevention of Alzheimer's disease by vitamin $\mathrm{E}$ and selenium trial (PREADViSE). JAMA Neurol 74(5):567-573.

6. Raszewski G, Chwedorowicz R, Chwedorowicz A, Rothenberg KG (2016) Homocysteine, antioxidant vitamins and lipids as biomarkers of neurodegeneration in Alzheimer's disease versus non-Alzheimer's dementia. Ann Agric Environ Med 23(1): 193-196.

7. Duvoix A, Blasius R, Delhalle S, Schnekenburger M, Morceau F, et al (2005) Chemopreventive and therapeutic effects of curcumin. Cancer Lett 223(2): 181-190.

8. Mishra S, Palanivelu K (2008) The effect of curcumin (turmeric) on Alzheimer's disease: An overview. Ann Indian Acad Neurol 11(1): 13 19.

9. Hamaguchi T, Ono K, Yamada M (2010) Review: Curcumin and Alzheimer's disease. CNS Neurosci Ther 16(5): 285-297.

10. Ringman JM, Frautschy SA, Cole GM, Masterman DL, Cummings JL (2005) A Potential role of the curry spice curcumin in Alzheimer's disease. Curr Alzheimer Res 2(2): 131-136

11. Kim JY, Choi DS, Jung MY (2003) Anti photo-oxidative activity of sesamol in methylene blue- and chlorophyll-sensitized photo-oxidation of Oil. J Agric Food Chem 51(11): 3460-3465.

12. Ohsawa T (1991) Sesamol and sesaminol as antioxidants. New Food Industry/Nyu Fudo Indasutori 33(6): 1-5.

13. Wynn JP, Kendrick A, Ratledge C (1997) Sesamol as an inhibitor of growth and lipid metabolism in mucorcircinelloides via its action on malic enzyme. Lipids 32(6): 605-610.

14. Ansari MA, Fatima Z, Hameed S (2014) Sesamol: A natural phenolic compound with promising anticandidal potential. J Pathog Volume 2014 (2014): P. 12.

15. Liu Z, Chen Y, Qiao Q, Sun Y, Liu Q et al. (2017) Sesamol supplementation prevents systemic inflammation-induced memory impairment and amyloidogenesis via inhibition of nuclear factor kappa B. Mol Nutr Food Res 61(5). DOI: 10.1002/mnfr.201600734.

16. Winblad B, Grossberg G, Fröhlich L, Farlow M, Zechner S, et al. (2007) IDEAL: A 6-month, double blind, placebo-controlled study of the first skin patch for Alzheimer disease. Neurol 69(4 Suppl 1): S14-22.

This work is licensed under Creative Commons Attribution 4.0 License DOI: $10.19080 /$ NAPDD. 2017.02555598
17.Camps P, Muñoz-Torrero D (2002) Cholinergic drugs in pharmacotherapy of Alzheimer's disease. Mini Rev Med Chem 2(1): 11-25.

18. Heinrich M (2004) Snowdrops: The heralds of spring and a modern drug for Alzheimer's disease. Pharm J 273(7330): 905-906.

19. Mashkovsky MD, Kruglikova-Lvova RP (1951) On the pharmacology of the new alkaloid galantamine. Farmakologia Toxicologia (Moscow) 14: $27-30$

20. Kovacic P, Osuna JA (2000) Mechanisms of anticancer agents: Focus on oxidative stress and electron transfer. Curr Pharm Des 6(3): 277-309.

21. Birks J, Harvey RJ (2006) Donepezil for dementia due to Alzheimer's disease. Cochrane Database Syst Rev 25(1): CD001190.

22. Chez MG, Buchanan TM, Becker M, Kessler J, Aimonovitch MC, et al. (2003) Donepezil hydrochloride: a double-blind study in autistic children. J Pediatr Neurol 1(2): 83-88.

23. Kovacic P, Somanathan R (2017) Mechanistic aspects of autism involving electron transfer, reactive oxygen species, oxidative stress, pollutants, antioxidants, cell signaling and genes. Nov Appro Drug Des Dev 1(3): p. 8.

24. Elnaggar YS, Etman SM, Abdelmonsif DA, Abdallah OY (2015) Intranasal piperine-loaded chitosan nanoparticles as brain-targeted therapy in Alzheimer's disease: Optimization, biological efficacy, and potential toxicity. J Pharm Sci 104(10): 3544-3556.

25. Yusuf M, Khan M, Khan RA, Ahmed B (2012) Preparation, characterization, in vivo and biochemical evaluation of brain targeted piperine solid lipid nanoparticles in an experimentally induced Alzheimer's disease model. J Drug Target 21(3): 300-311.

26. Chonpathompikunlert P, Wattanathorn J, Muchimapura S (2010) Piperine, the main alkaloid of Thai black pepper, protects against neurodegeneration and cognitive impairment in animal model of cognitive deficit like condition of Alzheimer's disease. Food Chem Toxicol 48(3): 798-802.

27. Elnaggar YS, Etman SM, Abdelmonsif DA, Abdallah OY (2015) Novel piperine-loaded tween-integrated monooleincubosomes as braintargeted oral nanomedicine in Alzheimer's disease: pharmaceutical, biological, and toxicological studies. Int J Nanomedicine 10: 54595473

\section{Your next submission with Juniper Publishers} will reach you the below assets

- Quality Editorial service

- Swift Peer Review

- Reprints availability

- E-prints Service

- Manuscript Podcast for convenient understanding

- Global attainment for your research

- Manuscript accessibility in different formats ( Pdf, E-pub, Full Text, Audio)

- Unceasing customer service

Track the below URL for one-step submission https://juniperpublishers.com/online-submission.php 